\title{
Effect of landings data disaggregation on ecological indicators
}

\author{
Dimitrios K. Moutopoulos ${ }^{1, *}$, Simone Libralato ${ }^{2}$, Cosimo Solidoro $^{2}$, Karim Erzini ${ }^{3}$, \\ Konstantinos I. Stergiou ${ }^{4,5}$
}

\author{
${ }^{1}$ Department of Fisheries and Aquaculture Technology, Technological Educational Institute of Western Greece, Nea Ktiria, \\ 30200 Mesolonghi, Greece \\ ${ }^{2}$ Department of Oceanography, Istituto Nazionale di Oceanografia e di Geofisica Sperimentale-OGS, Sgonico-Zgonik (TS), Italy \\ ${ }^{3}$ Centro de Ciencias do Mar (CCMAR), Universidade do Algarve, 8005-139 Faro, Portugal \\ ${ }^{4}$ Laboratory of Ichthyology, School of Biology, Department of Zoology, Aristotle University of Thessaloniki, \\ 54124 Thessaloniki, Greece \\ ${ }^{5}$ Institute of Marine Biological Resources and Inland Waters, Hellenic Centre for Marine Research, Aghios Kosmas, \\ 16604 Athens, Greece
}

\begin{abstract}
Ecological indicators calculated from landings data have been extensively used to evaluate the effects of fishing on marine ecosystems. However, few studies have tested the possible effects of gear and spatial aggregation of landings data on different ecological indices over a long-term period. To do this, we applied the Marine Trophic Index (MTI) and Fishing in Balance (FiB) index to Greek landings data disaggregated by gear and area for the period between 1928 and 2010. Aggregated data showed an increase in MTI due to expansion of fisheries that was also confirmed in most of the disaggregated analysis conducted by fishing subareas and main gear types. On the other hand, disaggregated landings by gear and area provided additional insights: while aggregated landings showed no decline in MTI, disaggregated landings showed that $63 \%$ of cases indicated an increase in MTI while $11 \%$ showed a decline. When small pelagics and other species were excluded, these values changed to $42 \%$ and $24 \%$, respectively. Thus, disaggregated data permitted the identification of ecologically meaningful critical situations with decreasing MTI, as has been observed in shallow enclosed gulfs in close proximity to large cities and/or for the main fishing grounds exploited for long periods by seiners (purse and beach). Moreover, disaggregating landings data by gear increased the ability of explaining observed trends, avoiding masking (averaging) effects and accounting for differential development and adaptability of different gear.
\end{abstract}

KEY WORDS: Fisheries landings - Trophic level - Gear effect - Multi-species fisheries · Mediterranean Sea

Resale or republication not permitted without written consent of the publisher

\section{INTRODUCTION}

Ecological indicators are considered a cornerstone for evaluating the state and trend of marine ecosystem health since they can summarize the effects of pressures on complex marine systems (Rice \& Rochet 2005). In this context, indicators based on fisherydependent data, such as landings, despite having intrinsic limitations for specific evaluations, have the advantage of being based on widely available data thus avoiding the costs of ad-hoc surveys and monitoring (Pauly 2013). Analysis of landings data, for instance, has permitted community evaluations (e.g. Caddy 2000, de Leiva Moreno et al. 2000, Pinnegar et al. 2003) extending far back in time (e.g. Fortibuoni et al. 2010). Assessments of ecological indicators are 
done using large scale units, such as large marine ecosystems (LME) or exclusive economic zones (EEZ) (Pauly et al. 1998, Coll et al. 2010). Nevertheless, the estimation of such indicators is affected by the aggregation of landing data, and in some cases the use of large spatial units can result in the masking of possible effects that are ecologically relevant at smaller spatial scales. In addition, the impact of estimating ecological indicators separately by gear type as opposed to estimates derived from aggregated total landings has never been tested formally. In this context, the disaggregation of fisheries landings by fishing area and fishing gear might help account for important local changes occurring over long periods, and will enable trends to be better identified in order to determine the mechanisms driving changes in food web dynamics due to alterations of fisheries practices.

The above-mentioned points are especially important for the Mediterranean (e.g. Demestre et al. 1997), and for Greek waters in particular (Stergiou et al. 1997a), where the multi-gear nature of the fisheries leads to homogenization of the historical evolution of landings. In addition, gear-specific differences in catchability and their different patterns of change through time can potentially mask the impact of fishing on marine resources when homogenized across gear types and areas. The spatial heterogeneity of Greek waters (e.g. topographic and bathymetric differences, existence of numerous small islands, extensive coastline) (Stergiou et al. 1997a) might further increase the masking effect, because fishers have adapted their fishing practices by using different gear types.

Herein, we evaluated how sensitive the estimation of ecological indices is to disaggregation of data by fishing subarea and gear over a period of $80 \mathrm{yr}$. We used the recently reconstructed Greek fisheries landings per gear and area between 1928 and 2010 (Moutopoulos \& Stergiou 2012, updated in Moutopoulos et al. in press). These time series include fisheries landings from all professional motor-vessels per subarea since the establishment of the national Greek fisheries statistics. The advantages of the reconstructed time series (as opposed to the official ones) are (1) the length of the time series (a continuous record from 1928 to 2010), (2) better spatial coverage (16 fishing subareas throughout the Greek seas), (3) homogeneity of the taxonomic composition of landings, and (4) separation of landings by fishing gear and subarea for all professional fishing motor-vessels.

We applied 2 metrics on different levels of aggregation of the original landing dataset: the Marine Tro- phic Index of landings (MTI, sensu Pauly \& Watson 2005) and the Fishing in Balance Index (FiB, Pauly et al. 2000). The MTI is high when fisheries target high trophic level (TL) species, but when these species decline and fisheries shift to low TL species, the MTI declines. Thus, it has been considered an indicator of the 'Fishing Down the Food Web' process (Pauly et al. 1998). Alternative fishing patterns have been proposed for explaining MTI changes, such as when low TL catches expand not for ecological reasons, but because of changes in fisheries targets ('fishing through', Essington et al. 2006), which is also related to better profits (Sethi et al. 2010). Moreover, when expansion of fisheries allows targeting more high predatory fishes, an increase in MTI is also observed ('fishing up', Branch et al. 2010). The FiB index was suggested to complement MTI trend analysis by accounting both the quantity of catches and their TL (Pauly et al. 2000), and by disentangling whether or not the latter is attributable either to the deliberate choice of targeting low TL species or to the effect of geographical expansion of fisheries on the TL of the catch.

In Greek waters, changes in mean TL across years have previously been evaluated on gear- and/or areaaggregated landings (1) per fishing subarea for the period 1964 to 1997 using the national landings (Stergiou \& Koulouris 2000), (2) per different TL ranges for the period 1950 to 2001 using the FAO landings (Stergiou 2005), (3) for Cyclades (Aegean Sea) for the period 1964 to 2003 using national landings (Pilling et al. 2009), and (4) for the period 1982 to 2007 using the national landings (Tsikliras et al. 2013). The present study is the first attempt to detect whether appropriate disaggregation of landings in terms of both area and gear will better enable trends in some ecological indices to be identified over an extended time period.

\section{MATERIALS AND METHODS}

We used the reconstructed Greek landings disaggregated by species (a total of 75 species, varying from 41 to 69 species by gear in each individual year), gear (i.e. trawls, purse-seines, beach-seines and other small-scale gear) and area (16 fishing subareas; Fig. 1) between 1928 and 2010 (Moutopoulos \& Stergiou 2012, updated in Moutopoulos et al. in press). Note that the period from 1940 to 1946 was not considered for the analyses due to extremely low landings during World War II and the ensuing Greek civil war (Serbetis 1949).

The TL of the species was taken from published information (Stergiou \& Karpouzi 2002) and comple- 


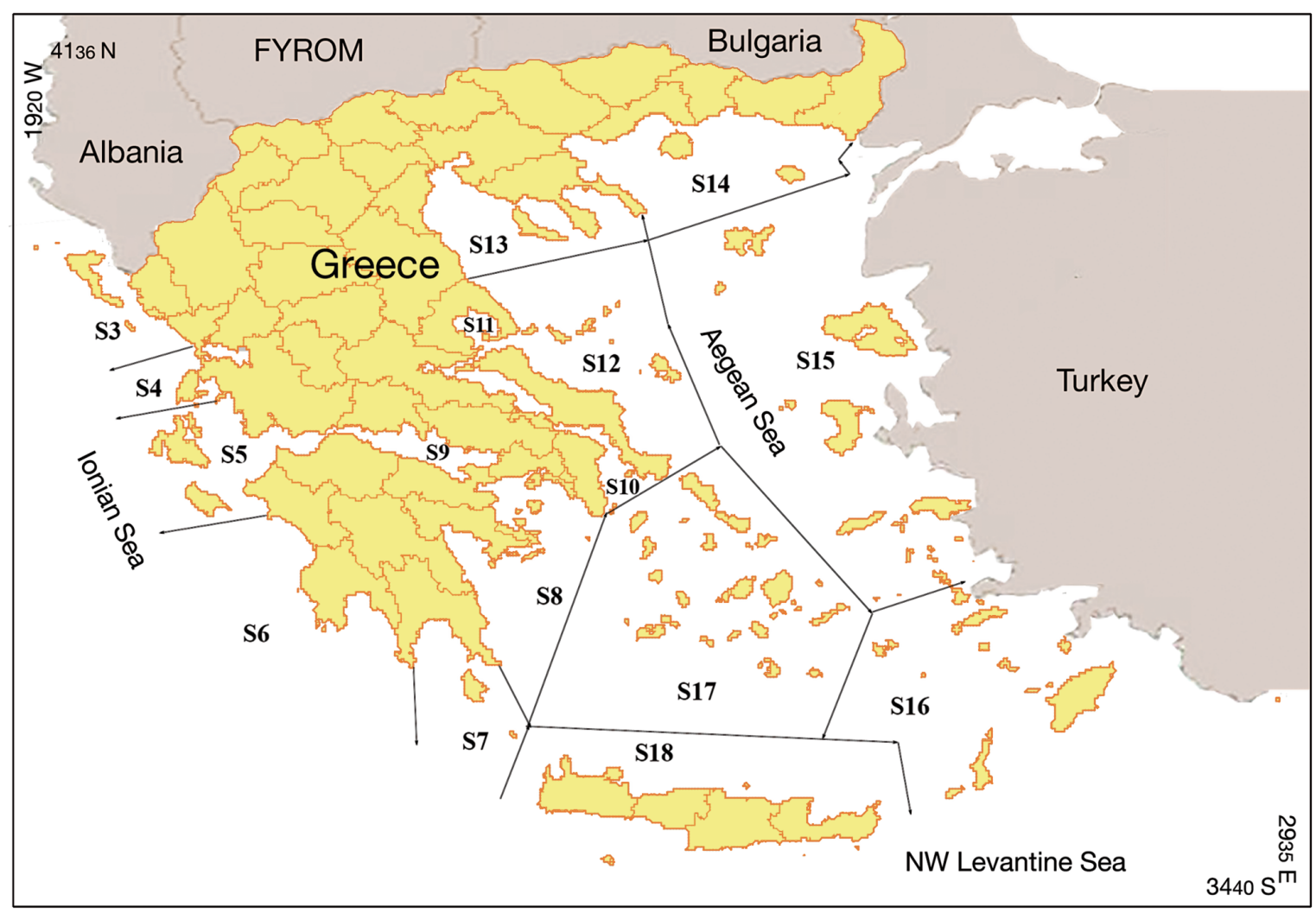

Fig. 1. Greek waters showing fishing subareas allocated by the Hellenic Statistical Authority (S3 to S18, enclosed by lines). Subareas 1 and 2 are outside Greek waters (Atlantic Ocean and North African Mediterranean coasts, respectively) and are exploited by the distant-water Greek vessels

mented by Mediterranean records included in FishBase (Froese \& Pauly 2013) for fish, and in SeaLifeBase (Palomares \& Pauly 2013) for cephalopods and crustaceans (see Appendix 1). For each gear/subarea combination, the MTI of landings for each year, $k\left(\mathrm{MTI}_{k}\right)$ was estimated as the average of TL of species $i$ weighted by the landings of species $i$ ( $Y_{i k}$ ) (Pauly \& Watson 2005):

$$
\mathrm{MTI}_{k}=\frac{\sum_{i}\left(\mathrm{TL}_{i} Y_{i k}\right)}{\sum_{i} Y_{i k}}
$$

FiB is calculated as follows (Pauly et al. 2000):

$$
\mathrm{FiB}=\log \left(\frac{Y_{k} \times \mathrm{TE}^{\mathrm{MTI}_{k}-1}}{Y_{1} \times \mathrm{TE}^{\mathrm{MTI}_{1}-1}}\right)
$$

where TE is the mean transfer efficiency of energy between trophic levels (assumed to be $10 \%$; Pauly \& Christensen 1995, Libralato 2008), $Y_{k}$ is the total landing for year $k$, and 1 refers to the first year in a time-series (in this case, 1928) used as a baseline.
The analysis was done both including and excluding the landings of (1) small- and medium-sized pelagics (i.e. Engraulis encrasicolus, Sardina pilchardus, Sardinella aurita, Spicara smaris and Sprattus sprattus) that are sensitive to bottom-up environmental factors (Cury et al. 2000); and (2) the 'other Osteichthyes' group reported in Moutopoulos \& Stergiou (2012), which aggregates a large number of species having wide ranges of trophic levels. The analysis with and without small-pelagics and 'other Osteichthyes' is hereafter referred to as analysis with and without SP-O.

To examine how sensitive the estimation of ecological indices is with respect to different levels of spatial aggregation per fishing gear, the analyses were carried out for (1) total landings (i.e. all gears and subareas combined), (2) landings per gear, (3) landings per fishing subarea, and (4) landings per gear and fishing subarea. A linear regression was fitted to the above species landings series with time and regressions, and slopes that were significantly ( $\mathrm{p}<$ 0.05) different from 0 were identified. 


\section{RESULTS}

Analyses of trends for landings and indicators are reported separately for the 4 cases of landings disaggregation, and the results derived from the regression analyses are summarized in Tables 1 \& 2 for landings including and excluding SP-O, respectively.

\section{Aggregated landings}

Total landings (i.e. all gears and subareas combined), FiB and MTI estimates exhibited a significant $(p<0.05)$ increase between 1928 and 2010 both for the landings with and without SP-O (Fig. 2a,f,k, Tables 1 \& 2; see column $\mathrm{G}$ and row $\mathrm{A}$ ).

\section{Landings disaggregated by gear}

Between 1928 and 2010, landings for all gear types increased with time (Fig. 2b-e), although landings decreased more or less gradually for all gear types between 1994 and 1999 (Fig. 2a). FiB significantly (p $<0.05$ ) increased for all gear types (Fig. 2f-j) over the entire period 1928 to 2010, whereas MTI (Fig. 2k-o) significantly $(p<0.05)$ increased for trawlers and small-scale vessels in analyses both with and without SP-O. Purse- and beach-seiner landings exhibited a significant decreasing trend in terms of MTI only in the case of landings without SP-O (Fig. 2m,n).

\section{Landings disaggregated per fishing area}

The results of the trend analysis conducted on the landings aggregating all gear types and disaggregated by fishing areas (i.e. subareas S3 to S18) are shown in rows 'A' of Tables $1 \& 2$. Landings and FiB estimates depicted the same trends, both for the spatially aggregated and disaggregated total landings, whether with or without SP-O (rows 'A-W' and 'AFiB' in Tables 1 \& 2, respectively). Conversely, MTI results for some subareas (4 and 5 out of 16 subareas for the landings with and without SP-O, respectively) exhibited different trends than those estimated from spatially aggregated landings. In particular, for the analysis with SP-O, MTI significantly $(\mathrm{p}<0.05)$ declined in subarea S12, whereas no significant $(\mathrm{p}>$ 0.05 ) trend was found in subareas S10, S11 and S13 (row 'A-MTI' in Table 1). The MTI calculated for landings without SP-O showed a significant $(\mathrm{p}<0.05)$ decreasing trend in subareas S8, S10, S11 and S12 (row 'A-MTI' in Table 2).

Table 1. 'Traffic light' table summarizing trends for indicators estimated from Greek total fisheries landings (i.e. all species combined) over the entire time series analysed (1928 to 2010). Results are reported for all gears combined, by gear, for all areas combined (G) and by area. Indicators include landing weight (W), Marine Trophic Index of landings (MTI) and Fishing in Balance Index (FiB). Green, red and yellow arrows indicated significant increasing, decreasing and no significant trends, respectively. The absence of trawl estimates in subarea S11 is due to the permanent ban on trawling in that area since 1967

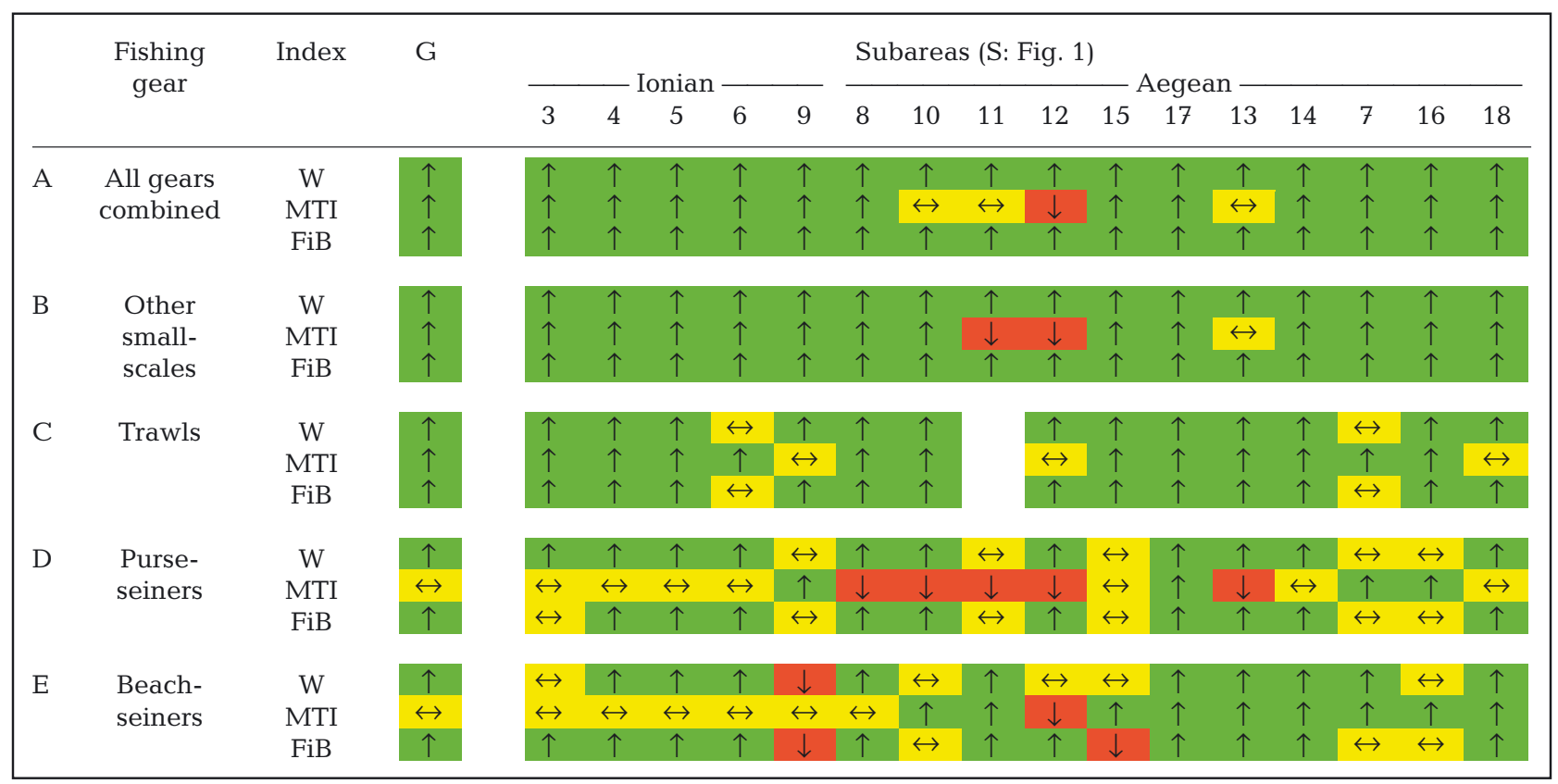


Table 2. 'Traffic light' table summarizing trends for indicators estimated from Greek fisheries landings excluding small pelagics and 'other Osteichthyes' group (see 'Materials and methods') over the entire time series analysed (1928 to 2010). Results are reported for all gears combined, by gear, for all areas combined (G) and by area. Indicators include landing weight (W), Marine Trophic Index of landings (MTI) and Fishing in Balance Index (FiB). Green, red and yellow arrows indicated significant increasing, decreasing and no significant trends, respectively. The absence of trawl estimates in subarea S11 is due to the permanent ban on trawling in that area since 1967

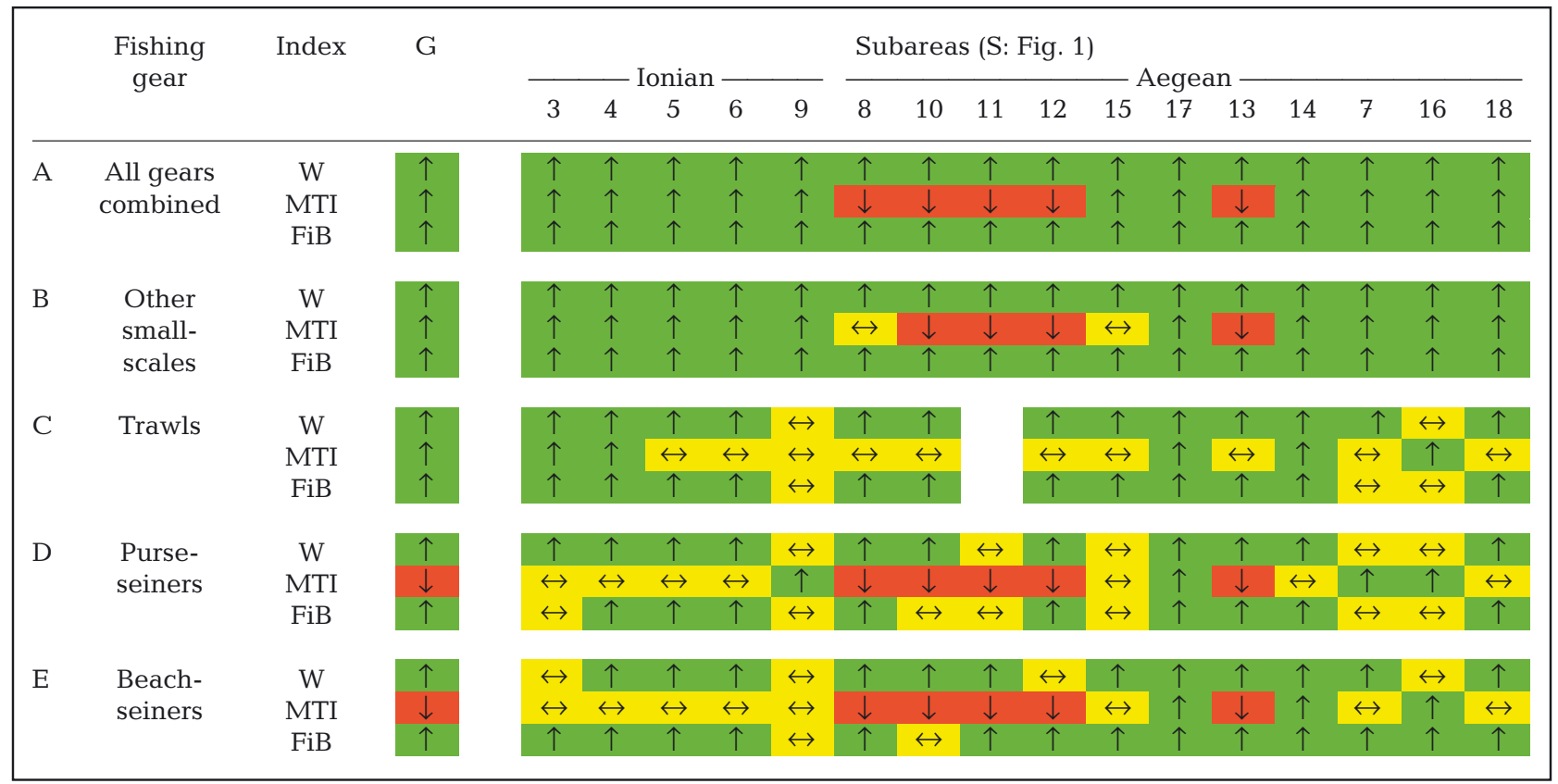

\section{Landings disaggregated per gear and fishing subarea}

Trend analyses conducted on landings per gear type and fishing subarea between 1928 and 2010 are shown in Tables 1 \& 2 for landings with and without SP-O, respectively (rows B to E). The tables summarize the results of the analysis of 382 time series between 1928 and 2010: 16 subareas $\times 4$ gear types $\times 3$ parameters $\times 2$ for the landings with/without SP-O, apart from subarea S11 for trawlers. The results showed that trends identified at any higher level of aggregation are not always confirmed when disaggregating landings per gear and fishing subarea. In particular, excluding non-significant trends, the trends on landings and FiB identified for trawls and other small-scale vessels at a national level are confirmed in all subareas. For MTI, although $63 \%$ of gear-area cases were increasing, $11 \%$ were declining; and when SP-O were excluded these values changed to $42 \%$ and $24 \%$ of the cases, respectively. In particular, positive trends on MTI for the above gears at a national level are not confirmed for subareas S11 and S12 (decreasing trends for small-scale vessels) or for S9 (non-significant trend for trawls)
(Table 1). Similarly, for the analysis performed on landings with SP-O, the positive trend of MTI for trawls and other small-scale vessels on a national basis was not confirmed for subarea S9 (no significant MTI trend for trawls) or for subareas S10, S11, S12 and S13 (significant [p < 0.05] decreasing MTI trend for other small scale vessels) (Table 2). Purseand beach-seiners, however, showed several contrasting trends between aggregated and disaggregated landings (by gear and subarea). For instance, when including SP-O landings (Table 1) significant $(p<0.05)$ declining trends in MTI were found for subareas S8, S10, S11, S12 and S13 for purse-seiners and for subarea S12 for beach-seiners. Moreover, significant $(p<0.05)$ declining trends were also found for beach-seine landings in subarea S9 and for FiB in subareas S9 and S15. Analyses performed without SP-O (Table 2) for purse- and beach-seiners showed contrasting trends between aggregated and disaggregated landings only for MTI in subareas S9, S17, S7, S16 (purse-seines) and S17, S14 and S16 (beachseines). Fig. 3 shows the time series of landings for subareas S8, S10, S11, S12 and S13 that showed declining MTI and make up the main part of the Greek landings (approximately $70 \%$ of the total landings). 

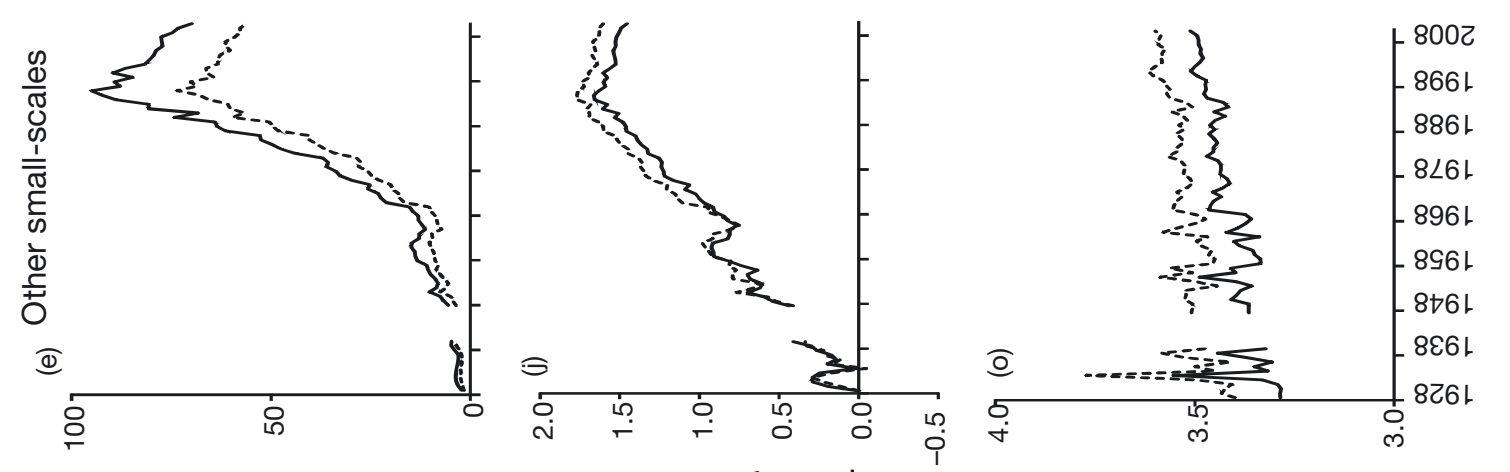

$\begin{array}{ll} & = \\ 0 & 0 \\ 0 & 0 \\ 0 & 3 \\ 0 & 0 \\ 0 & 0 \\ 0 & 0 \\ 0 & 3 \\ 0 & 0 \\ 0 & 0 \\ 0 & 0 \\ 0 & 0 \\ 0 & 0 \\ 0 & 3 \\ 0 & 0 \\ 0 & 0 \\ 0 & 0 \\ 3 & 0 \\ 0 & 0 \\ 0 & 0\end{array}$
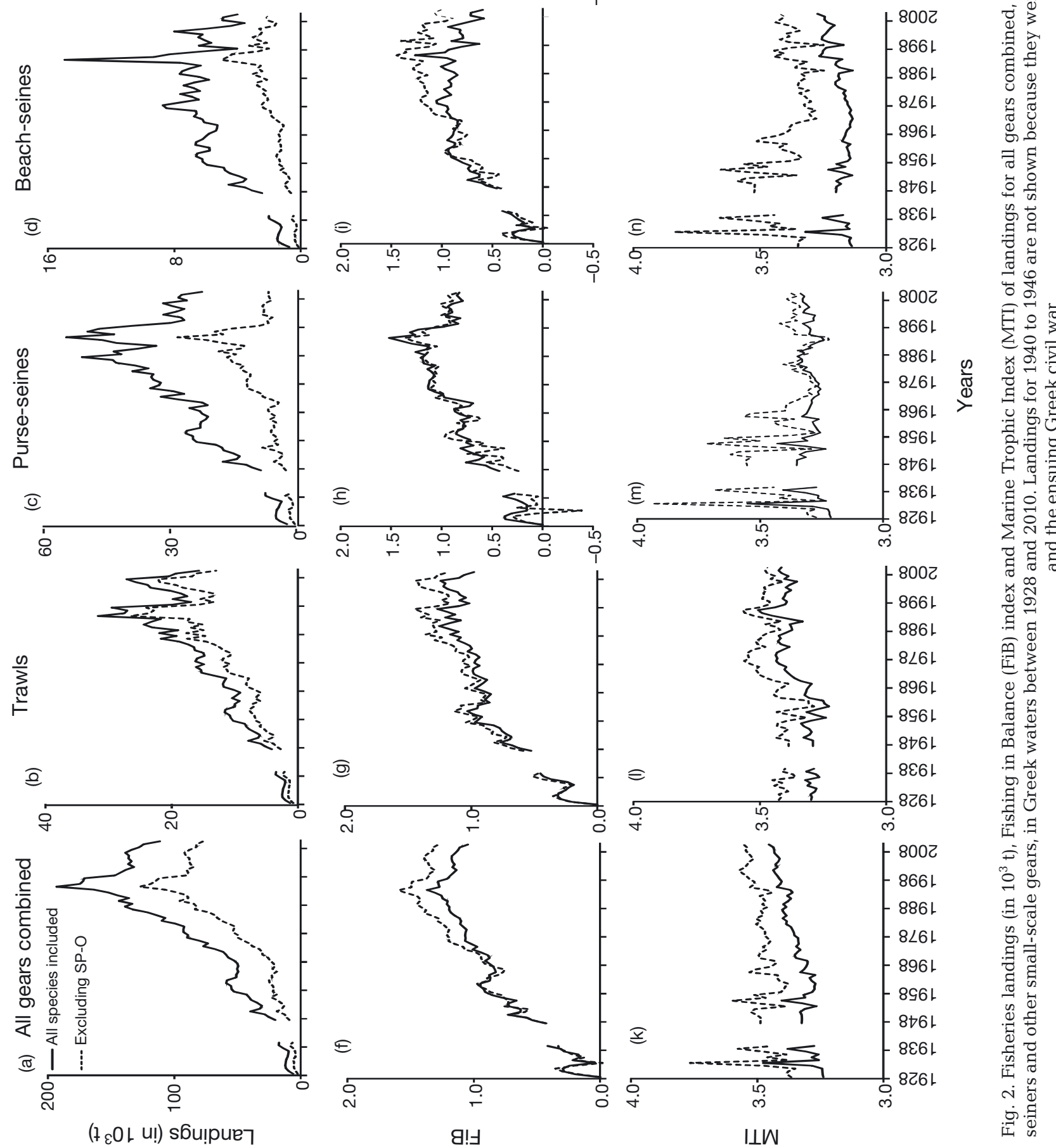


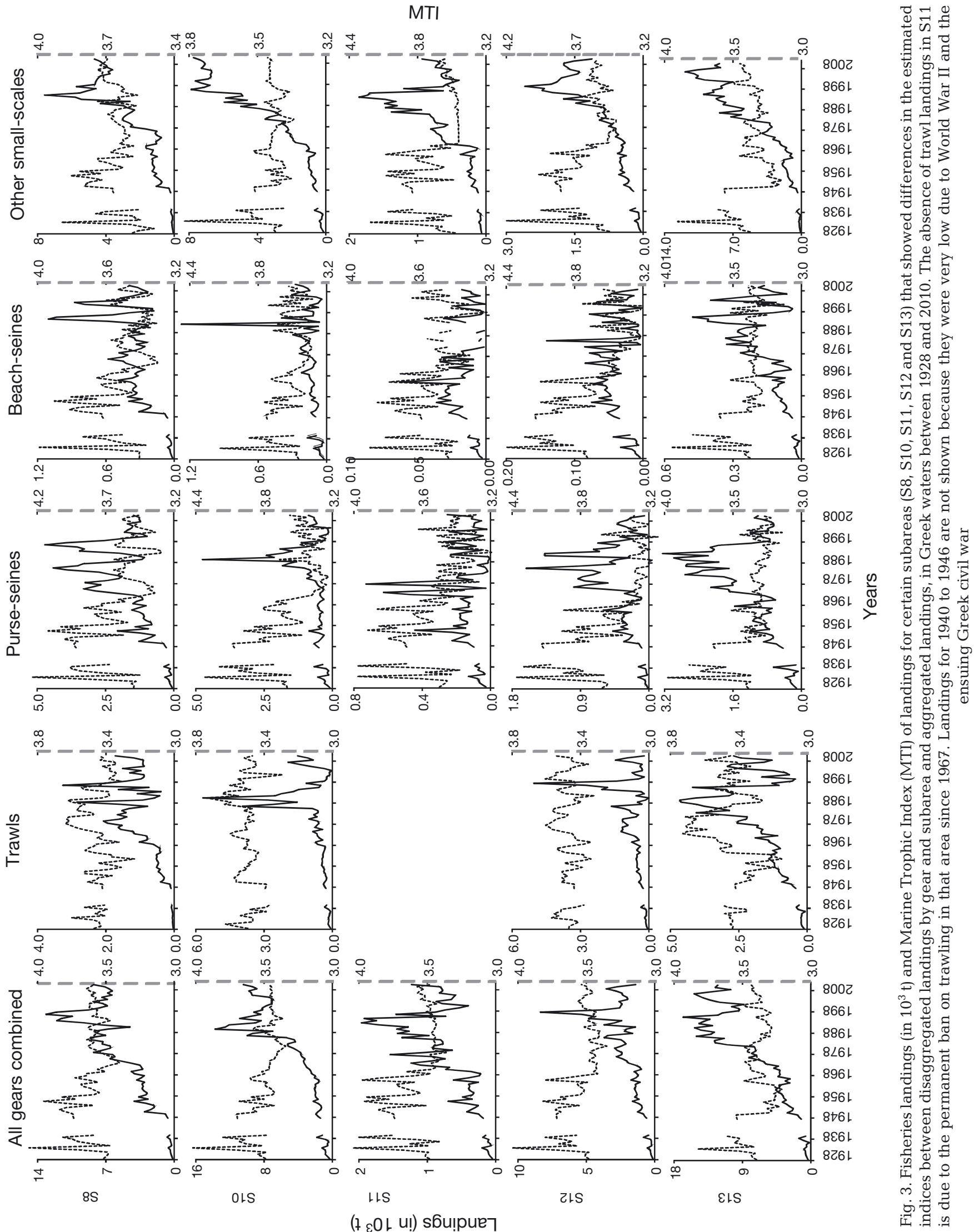




\section{DISCUSSION}

The present study tests the possible effects of spatial and gear aggregation of long-term fisheries landings data on ecological indices. The data used here suffer from certain limitations due to (1) the quality of the national landings data (Moutopoulos \& Koutsikopoulos 2014), (2) the different number of species recorded through time (i.e. 45 species between 1928 and 1949; 41 to 43 species between 1950 and 1963; 60 species between 1964 and 1969; and 68 to 69 species between 1970 and 2010) and (3) the spatial variability of species-specific TL (i.e. a mean value per species was used here; see Appendix 1). Yet they are useful for the estimation of ecological indices for measuring community-wide changes and assessing the state of the marine ecosystem (Rochet et al. 2005, Fortibuoni et al. 2010).

Aggregated Greek landings data showed an increase in landings, MTI and FiB; thus indicating a 'fishing-up' the food web process (sensu Litzow \& Urban 2009). However, disaggregated landings by subarea, although confirming the fishing-up process for many Greek subareas (63\% and $42 \%$ of geararea combinations when analyzing data with and without SP-O, respectively), highlight a decrease in MTI over time in some subareas $(11 \%$ and $24 \%$ of gear-area combinations when analyzing data with and without SP-O, respectively); i.e. subarea S12 when analysing data with SP-O (Table 1) and subareas S8, S10, S11, S12 and S13 when analysing data without SP-O (Table 2). Local fishing-down cases were unnoticed when analysing aggregated data. The subareas in which MTI declined are either enclosed gulfs in close proximity to large cities (i.e. subareas S10, S11, S13) and/or are the main fishing grounds (extended continental shelves, smooth muddy/sandy bottoms; i.e. subareas S8, S12 and S13) (Stergiou et al. 1997a) where exploitation was historically more intense than in the remaining fishing subareas. The first signs of overexploitation in areas in close proximity to large cities (i.e. subareas S10 and S13) were identified in the early 1950s (Ananiadis 1970, Moutopoulos \& Stergiou 2011), thus supporting the results obtained here with disaggregated data by area (see also Fig. 3).

Most of the species targeted by the different Greek fisheries are not highly migratory, but develop their biological cycle within a spatial scale of the order of hundreds of kilometers (i.e. 66 out of 75 total recorded species; Appendix 1); thus, results based on landings disaggregated by subarea are ecologically meaningful. Moreover, given the large distances and the relatively small degree of ecological connections between some Greek subareas (Ionian vs. North and South Aegean and Levantine subareas, Fig. 1; for a review see Stergiou et al. 1997a), the analysis of aggregated data has limited ecological sense and is prone to masking effects. In fact, ecological connections (e.g. trophic or reproductive migrations) may link distant areas only for large pelagics, while for other groups (more consistent in the landings) may have a shorter range of ecological effects.

Different fishing subareas reflect distinct units in terms of species assemblages and populations (Labropoulou 2007), and the compensation and dilution of the effects for larger areas (i.e. analysis of total Greek landings) is not ecologically meaningful. Yet, subareas are not closed systems and a certain degree of ecological exchange occurs, especially for contiguous subareas such as the Ionian subareas (i.e. S3 to S6). Ecosystem assessments through ecological indicators, therefore, need to be carried out at the proper ecological spatial unit. Analysis of landing data by homogeneous subareas in terms of oceanography, ecology and fisheries is therefore recommended both for detection of fisheries effects and for providing management advice (Stergiou \& Pollard 1994).

Landings disaggregated by subarea and gear showed increasing MTI trends in several subareas, mostly in southern Greek waters (e.g. subareas S16 and S17) for analyses performed with and without SP-O (Tables $1 \& 2$ ). In accordance with the fact that economics drives patterns in fisheries development (Sethi et al. 2010), the increasing trends in landingsbased indicators are in agreement with the temporal intensification and spatial expansion of the Greek fisheries, as observed for all fishing gears and in most subareas (Tables $1 \& 2$ ). This was triggered by the modernization of the Greek fisheries through the establishment of European funds oriented to the fisheries sector that resulted in the spatial expansion of operational activities from $200 \mathrm{~m}$ to more than $400 \mathrm{~m}$ (Anonymous 2001), and increase in operational time spent at sea from 150 to 170 fishing days in 1938 (Moutopoulos \& Stergiou 2011) to about 240 fishing days in the late 1990s (Anonymous 2001). Such expansions are captured by the FiB index, which is generally increasing (Fig. 2, Tables 1 \& 2). Moreover, the expansion of the fisheries can explain the important increase in some target species groups in the landings, such as the proportion of large pelagics (for small-scale fisheries) and large demersals (both for trawls and small-scale fisheries) (Fig. 4) that probably resulted from the increased capabilities of Greek fleets to exploit the open seas and great depths. 


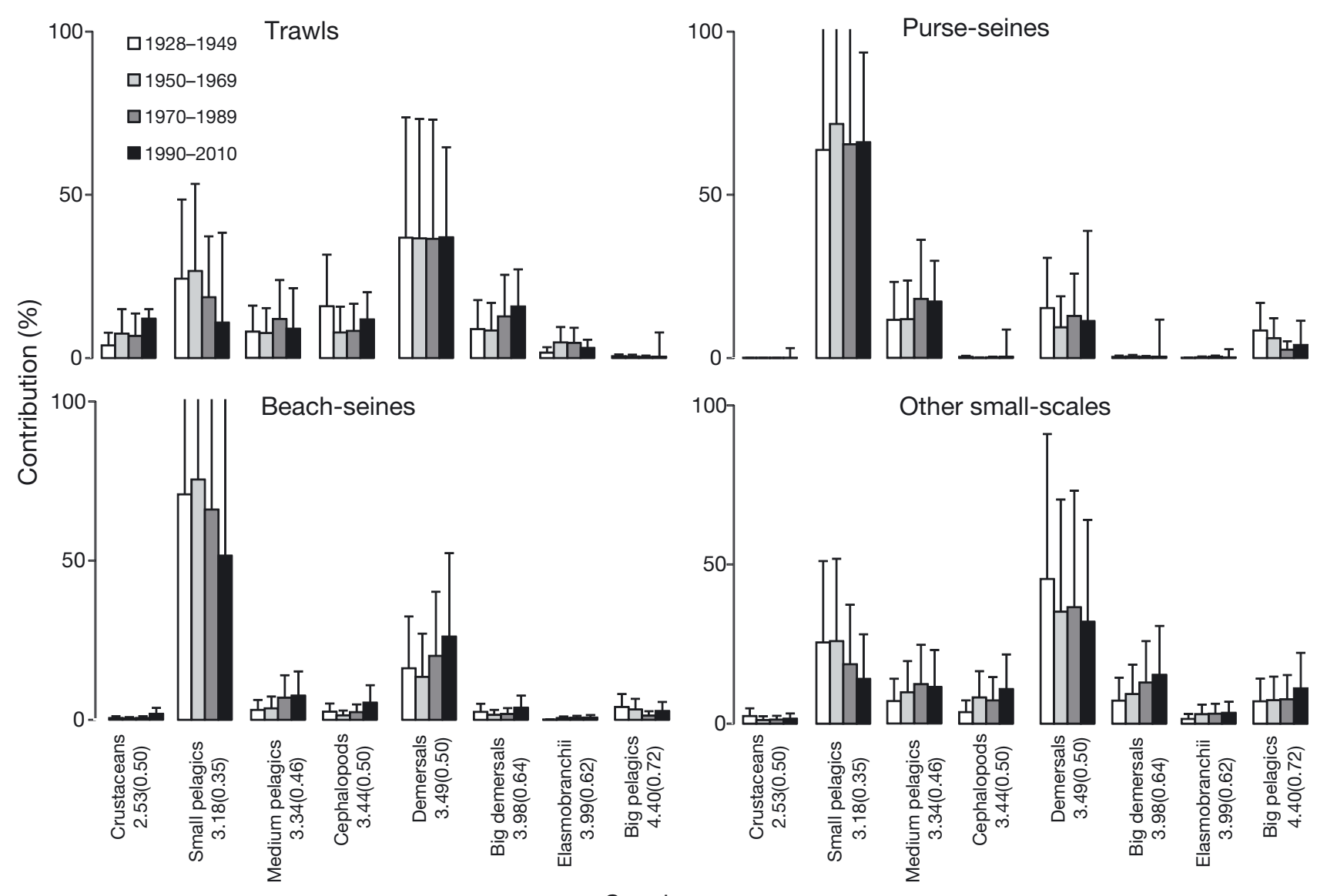

\section{Species groups}

Fig. 4. Mean ( $(\mathrm{SD})$ composition (\%) of landings per species group (see Appendix 1) and time period for each gear. Numbers indicate the average (SD) trophic level for each group

More cases with declining or not significantly changing MTI were observed for purse- and beachseiners (Tables $1 \& 2$ ) than for trawlers and other small-scale vessels, a fact related to gear characteristics. In fact, purse- and beach-seiners (1) are generally species-specific (i.e. more than $75 \%$ of purseand beach-seine landings are derived from 5 and 6 species, respectively, in each of the 16 subareas; Moutopoulos \& Stergiou 2012), targeting small- and medium-sized pelagic fish species with lower and narrow TL ranges (from 3.42 to 3.65 ; Fig. 4); (2) exploit specific habitats (i.e. purse-seines: pelagic zone; beach-seines: shallow, inshore areas and enclosed gulfs at depths $<100 \mathrm{~m}$ ); and (3) have generally been less modernized through time when compared to trawlers (e.g. since 1980 beach-seines have been excluded from all beneficial European Union projects; Papaconstantinou \& Farrugio 2000).

On the other hand, trawlers and other small-scale vessels are characterized by a large number of target species (more than 10 species in 10 subareas, and more than 15 species in 13 subareas contributed more than $75 \%$ of the trawl and other small-scale vessel landings, respectively) and/or continuous fleet modernization. In particular, trawls and small-scale vessels generally target a large number of demersal and benthopelagic species with a wide range of trophic levels (from 3 to 4 ; Fig. 4). Trawling is generally considered a high impact fishing activity, being flexible enough, through technological improvements, to expand both horizontally and vertically in new areas (Anonymous 2001). Moreover, in the Mediterranean Sea, trawlers have low species selectivity (Stergiou et al. 1996, 1997b) and are highly flexible with respect to the exploitation of different habitats (Anonymous 2001), with their catch data being characterized by seasonal and annual changes in species compositions (Pranovi et al. 2000) and/or exploitation of new species of commercial interest (Libralato et al. 2004). The same is also true for the other small-scale vessels which use a large number of different gear types and gear sizes (i.e. gill and trammel nets of different mesh sizes, longlines of different hook sizes) to target a large number of species (Tzanatos et al. 2005) belonging to 
a wide spectrum of TLs (Stergiou et al. 2007). For instance, gears employed in other small-scale vessels target the high TL species (i.e. Polyprion americanus; Appendix 1) and/or the large mature individuals inhabiting deep waters that were previously inaccessible to fisheries (e.g. Merluccius merluccius; Anonymous 2001). Therefore, trawl and other small-scale fisheries can adapt better to the topographic heterogeneity of the Greek Seas (Stergiou et al. 1997a) and to ecosystem changes (i.e. species composition) than beach- and purse-seiners, and this can explain the dominance of the increase in landings, FiB and MTI for these fisheries in most of the subareas.

The decline of MTI for the landings without SP-O for small-scale vessels, purse- and beach-seiners in subareas S10, S11, S12 and S13 deserves special attention. These gear types showed different targets and socio-economic drivers (although interrelated) when compared to trawls, for which the positive MTI trends exhibited in the above subareas might be influenced by the restriction measures issued (i.e. trawl banning during the whole year, 9 mo and 8 mo for S11, S13 and S10, respectively). Thus, it is unlikely that the MTI decline might be attributed to market-driven changes. Rather, there seems to be an ecological pattern occurring in the area and emerging in the landings (i.e. in these subareas, fishing down the food web is occurring). This conclusion can be extended (with caution) to subarea S8, where only purse-seiners and beach-seiners have declining MTI.

Nevertheless, given the above arguments on gear selectivity and flexibility, purse- and beach-seiners are less adaptive to changes in the fish community: the possibility that they can be regarded as sensitive gears, able to provide early signals of overfishing, might be further analysed.

In general, disaggregation of landings revealed declines of MTI and possible fishing-down food web effects that were previously masked at aggregated levels. Notably, there were very few cases in which negative trends at the aggregated level resulted in positive trends for disaggregated landings. This happened only for purse- and beach-seiners for the landings without SP-O (Table 2), which showed negative MTI trends for aggregated landings but positive MTI trends for disaggregated landings in subareas S9, S17, S7, S16 (purse-seines) and S17, S14 and S16 (beach-seines). This is in line with a possible geographical expansion of the fisheries and 'fishing-up' occurring in these subareas.

Overall, the disaggregation of landings by gear and subarea help in examinig common patterns that can be critical and that can be studied in more detail.
Likewise, the massive exploitation of the Manila clam Tapes philippinarum with mechanical dredges in Venice Lagoon during the mid-1990s could have been regarded as fishing-through (sensu Essington et al. 2006), when in fact it was fishing-down when landings were analysed by gear (see Fig. 2 in Libralato et al. 2004).

\section{CONCLUSIONS}

A first step towards identifying the state of the marine ecosystem is to determine key indicators that respond to fishing pressure (Rochet et al. 2005). The present study tests the possible effects of spatial and gear aggregation of the Greek reconstructed fisheries landings data over a long period on different ecological indices. The results of the analysis of disaggregated landings by fishing gear and/or subarea showed considerable differences in the insights regarding the trophic structure of the Greek Seas. In particular, some possibly critical issues (e.g. fishingdown processes) were unnoticed when aggregated data were used, while changes that are meaningful in ecological terms emerged when the analysis was carried out by gear and subarea.

Acknowledgements. The authors thank 3 anonymous reviewers for their comments and suggestions.

\section{LITERATURE CITED}

Ananiadis KI (1970) The effects of trawl fishing on the stocks of different commercial species in Greek waters. Proceedings of the Hydrological Institute of Athens Academy, p 493-497

Anonymous (2001) Patterns and propensities in Greek fishing effort and catches. Report to the EU (DGXIV), Project 00/018

Branch TA, Watson R, Fulton EA, Jennings S and others (2010) The trophic fingerprint of marine fisheries. Nature 468:431-435

> Caddy JF (2000) Marine catchment basin effects versus impacts of fisheries on semi-enclosed seas. ICES J Mar Sci 57:628-640

Coll M, Piroddi C, Kaschner K, Ben Rais Lasram F and others (2010) The biodiversity of the Mediterranean Sea: estimates, patterns and threats. PLoS ONE 5:e11842

Cury PM, Bakun A, Crawford RJM, Jarre A, Quinones RA, Shannon LJ, Verheye HM (2000) Small pelagics in upwelling systems: patterns of interaction and structural changes in 'wasp-waist' ecosystems. ICES J Mar Sci 57: 603-618

de Leiva Moreno JI, Agostini VN, Caddy JF, Carocci F (2000) Is the pelagic-demersal ratio from fishery landings a useful proxy for nutrient availability? A preliminary data exploration for the semi-enclosed seas around Europe. ICES J Mar Sci 57:1091-1102 
Demestre M, Sbrana M, Alvarez F, Sanchez P (1997) Analysis of the interaction of fishing gear in Mullus barbatus fisheries of the Western Mediterranean. J Appl Ichthyol 13:49-56

Essington TE, Beaudreau AH, Wiedenmann J (2006) Fishing through marine food webs. Proc Natl Acad Sci USA 103: 3171-3175

Fortibuoni T, Libralato S, Raicevich S, Giovanardi O, Solidoro C (2010) Coding early naturalists' accounts into long-term fish community changes in the Adriatic Sea (1800-2000). PLoS ONE 5:e15502

Froese R, Pauly D (eds) (2013) FishBase. www.fishbase.org (accessed Dec 2012)

Labropoulou M (2007) Fish community structure and diversity of demersal species. In: Papaconstantinou C, Zenetos A, Vassilopoulou V, Tserpes G (eds) State of Hellenic fisheries. Hellenic Centre for Marine Research, Athens, p 35-42

Libralato S (2008) System omnivory index. In: Jørgensen SE, Fath BD (eds) Ecological indicators. Encyclopedia of ecology, Vol. 4, Elsevier, Oxford, p 3472-3477

Libralato S, Pranovi F, Raicevich S, Da Ponte F and others (2004) Ecological stages of the Venice Lagoon analysed using landing time series data. J Mar Syst 51:331-344

Litzow MA, Urban D (2009) Fishing through (and up) Alaskan food webs. Can J Fish Aquat Sci 66:201-211

Moutopoulos DK, Koutsikopoulos C (2014) Fishing strange data in national fisheries statistics of Greece. Mar Policy 48:114-122

Moutopoulos DK, Stergiou KI (2011) The evolution of the Greek fisheries during 1928-1939. Acta Adriat 52: 183-200

Moutopoulos DK, Stergiou KI (2012) Spatial disentangling of Greek fisheries landings by fishery during 1928-2007. J Biol Res (Thessalon) 18:265-279

Moutopoulos DK, Tsikliras AC, Stergiou KI (in press) Reconstruction of Greek fishery catches per fishing gear and area (1950-2010). Fisheries Centre Research Reports, Fisheries Center, University of British Columbia, Vancouver

Palomares MLD, Pauly D (eds) (2013) SeaLifeBase. www. sealifebase.org (accessed Dec 2013)

Papaconstantinou C, Farrugio H (2000) Fisheries in the Mediterranean. Medit Mar Sci 1:5-18

Pauly D (2013) Fisheries: Does catch reflect abundance? Point, Hilborn R, Branch TA. Nature 494:303-306

Pauly D, Christensen V (1995) Primary production required to sustain global fisheries. Nature 374:255-257

Pauly D, Watson R (2005) Background and interpretation of the 'Marine Trophic Index' as a measure of biodiversity. Phil Trans R Soc Lond B Biol Sci 360:415-423

Pauly D, Christensen V, Dalsgaard J, Froese R, Torres F Jr (1998) Fishing down marine food webs. Science 279: 860-863

Pauly D, Christensen V, Walters C (2000) Ecopath, Ecosim and Ecospace as tools for evaluating ecosystem impact of fisheries. ICES J Mar Sci 57:697-706

Pilling GM, Apostolaki P, Failler P, Floros C and others (2009) Assessment and management of data-poor fisheries. In: Payne A, Cotter J, Potter T (eds) Advances in fisheries science: 50 years on from Beverton and Holt. Blackwell Publishing, Oxford, p 280-305

Pinnegar JK, Polunin NVC, Badalarnenti F (2003) Longterm changes in the trophic level of western Mediterranean fishery and aquaculture landings. Can J Fish Aquat Sci 60:222-235

> Pranovi F, Raicevich S, Franceschini G, Farrace MG, Giovanardi $O$ (2000) Rapido trawling in the northern Adriatic Sea: effects on benthic communities in an experimental area. ICES J Mar Sci 57:517-524

Rice JC, Rochet MJ (2005) A framework for selecting a suite of indicators for fisheries management. ICES J Mar Sci 62:516-527

Rochet MJ, Trenkel V, Bellail R, Coppin F and others (2005) Combining indicator trends to assess ongoing changes in exploited fish communities: diagnostic of communities off the coasts of France. ICES J Mar Sci 62:1647-1664

Serbetis Ch (1949) The situation of the Greek fishery on 1947. Bulletin of fisheries research laboratory 1948. Ministry of National Economy-Fisheries Directorate, Athens, p 87-93

Sethi SA, Branch TA, Watson R (2010) Fishery development patterns are driven by profit but not trophic level. Proc Natl Acad Sci USA 107:12163-12167

Stergiou KI (2005) Fisheries impact on trophic levels: longterm trends in Hellenic waters. In: Papathanasiou E, Zenetos A (eds) State of the Hellenic marine environment. Hellenic Centre for Marine Research, Athens, p 326-329

Stergiou KI, Karpouzi VS (2002) Feeding habits and trophic levels of Mediterranean fish. Rev Fish Biol Fish 11: 217-254

Stergiou KI, Koulouris M (2000) Fishing down the marine food webs in the Hellenic Seas. In: Briand F (ed) Fishing down the Mediterranean food webs? CIESM, Monaco, p 73-78

Stergiou KI, Pollard D (1994) A spatial analysis of the commercial fisheries catches from the Greek Aegean Sea. Fish Res 20:109-135

Stergiou KI, Petrakis G, Politou CY (1996) Small-scale fisheries in the South Euboikos Gulf (Greece): species composition and gear competition. Fish Res 26:325-336

Stergiou KI, Christou ED, Georgopoulos D, Zenetos A, Souvermezoglou C (1997a) The Hellenic seas: physics, chemistry, biology and fisheries. Oceanogr Mar Biol Annu Rev 35:415-538

> Stergiou KI, Politou CY, Petrakis G (1997b) Selectivity experiments in the NE Mediterranean: the effects of trawl cod-end mesh size on species diversity and discards. ICES J Mar Sci 54:774-786

Stergiou KI, Moutopoulos DK, Casal HJA, Erzini K (2007) Trophic signatures of small-scale fishing gears: implications for conservation and management. Mar Ecol Prog Ser 333:117-128

Tsikliras AC, Tsiros VZ, Stergiou KI (2013) Assessing the state of Greek marine fisheries resources. Fish Manag Ecol 20:34-41

> Tzanatos E, Dimitriou E, Katselis G, Georgiadis M, Koutsikopoulos C (2005) Composition, temporal dynamics and regional characteristics of small-scale fisheries in Greece. Fish Res 73:147-158 
Appendix 1. Trophic level (TL) and their standard error (SE) estimates for species landed from Greek waters

\begin{tabular}{|c|c|c|c|c|c|}
\hline $\begin{array}{l}\text { Groups } \\
\text { Species }\end{array}$ & $\mathrm{TL}$ & SE & $\begin{array}{l}\text { Groups } \\
\text { Species }\end{array}$ & TL & $\mathrm{SE}$ \\
\hline Demersals & & & Rhinobatidae & 4.05 & 0.69 \\
\hline Boops boops & 2.92 & 0.28 & Squalidae & 4.30 & 0.67 \\
\hline Diplodus annularis & 3.36 & 0.44 & Small pelagic & & \\
\hline Diplodus sargus & 3.17 & 0.41 & Engraulis encrasicolus & 3.43 & 0.45 \\
\hline Gurnard & 3.39 & 0.38 & Sardina pilchardus & 3.15 & 0.37 \\
\hline Merlangius merlangus & 4.40 & 0.77 & Sardinella aurita & 3.20 & 0.32 \\
\hline Micromesistius poutassou & 3.89 & 0.62 & Spicara flexuosa & 3.30 & 0.39 \\
\hline Mullus barbatus & 3.27 & 0.45 & Spicara maena & 3.15 & 0.22 \\
\hline Mullus surmuletus & 3.38 & 0.49 & Spicara smaris & 3.05 & 0.20 \\
\hline Oblada melanura & 3.10 & 0.20 & Sprattus sprattus & 3.00 & \\
\hline Mugilidae & 2.42 & 0.21 & Medium pelagic & & \\
\hline Osteichthyes & 3.10 & 0.50 & Belone belone & 3.48 & 0.45 \\
\hline Pagellus erythrinus & 3.36 & 0.46 & Scomber japonicus & 3.10 & 0.43 \\
\hline Pagrus pagrus & 3.75 & 0.60 & Scomber scombrus & 3.90 & 0.66 \\
\hline Sarpa salpa & 2.13 & 0.07 & Trachurus mediterraneus & 3.50 & 0.48 \\
\hline Scorpaenidae & 3.81 & 0.63 & Trachurus trachurus & 3.65 & 0.51 \\
\hline Serranus spp. & 3.66 & 0.56 & Big pelagic & & \\
\hline Solea solea & 3.23 & 0.43 & Auxis thazard & 4.50 & 0.80 \\
\hline Sparus aurata & 3.42 & 0.56 & Euthynnus alletteratus & 4.50 & 0.80 \\
\hline Triglidae & 3.50 & 0.52 & Katsuwonus pelamis & 4.40 & 0.76 \\
\hline Umbrina cirrosa & 3.51 & 0.55 & Pomatomus saltatrix & 4.50 & 0.80 \\
\hline Zeus faber & 4.45 & 0.79 & Sarda sarda & 4.50 & 0.80 \\
\hline Big demersal & & & Seriola dumerili & 4.10 & 0.66 \\
\hline Dentex dentex & 4.50 & 0.73 & Thunnus spp. & 4.30 & 0.73 \\
\hline Dentex macrophthalmus & 3.40 & & Xiphias gladius & 4.50 & 0.67 \\
\hline Dicentrarchus labrax & 3.80 & 0.60 & Cephalopods & & \\
\hline Epinephelus alexandrinus & 4.50 & 0.73 & Loliginidae & 3.20 & \\
\hline Epinephelus marginatus & 3.91 & 0.66 & Loligo sp. & 3.50 & \\
\hline Helicolenus dactylopterus & 3.84 & 0.64 & Octopodidae & 3.20 & \\
\hline Lophius spp. & 4.35 & 0.65 & Octopus vulgaris & 4.10 & \\
\hline Merluccius merluccius & 4.09 & 0.68 & Sepia officinalis & 3.20 & \\
\hline Polyprion americanus & 4.10 & 0.64 & Crustaceans & & \\
\hline Psetta maxima & 4.00 & 0.63 & Carcinus aestuarii & 2.20 & \\
\hline Spondyliosoma cantharus & 3.29 & 0.56 & Hommarus gammarus & 2.60 & \\
\hline Elasmobranchii & & & Natantia & 2.20 & \\
\hline Mustelus spp. & 3.80 & 0.50 & Nephrops norvegicus & 2.60 & \\
\hline Raja clavata & 3.90 & 0.61 & Penaeus kerathurus & 2.70 & \\
\hline Raja spp. & 3.90 & 0.62 & Other cephalopods and crustaceans & 2.88 & \\
\hline
\end{tabular}

Editorial responsibility: Jake Rice, Ottawa, Ontario, Canada
Submitted: February 14, 2013; Accepted: May 9, 2014

Proofs received from author(s): July 27, 2014 